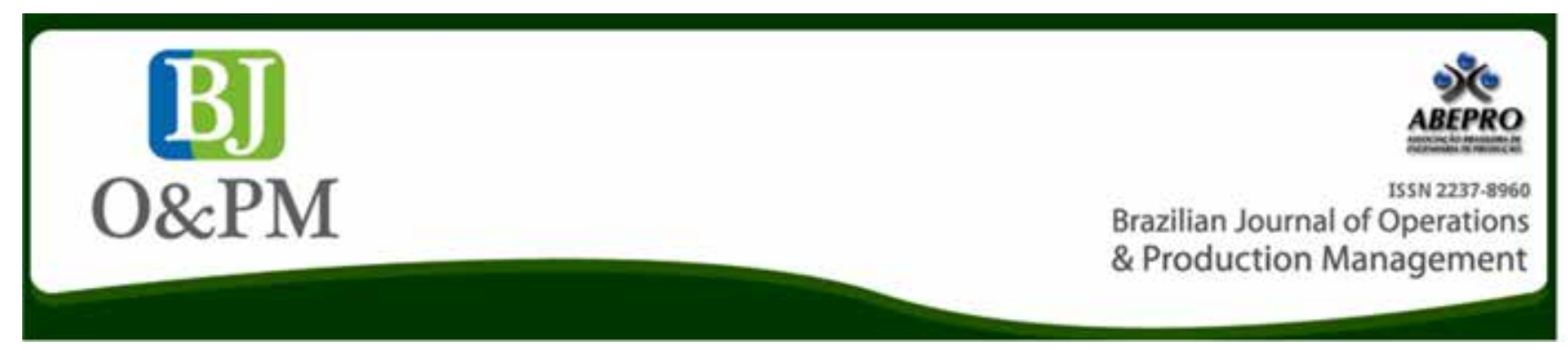

\title{
OPPORTUNITIES \& CHALLENGES FOR OPERATIONS MANAGEMENT - A POINT OF VIEW FROM THE 2018 POMS INTERNATIONAL CONFERENCE IN RIO
}

\author{
Adriana Leiras \\ adrianaleiras@puc-rio.br \\ Industrial Engineering Department, \\ Pontifical Catholic University of \\ Rio de Janeiro - PUC-Rio, Rio de \\ Janeiro, RJ, Brazil.
}

Tharcisio Cotta Fontainha fontainha@pep.ufrj.br Production Engineering Program, Federal University of Rio de Janeiro - UFRJ, Rio de Janeiro, RJ, Brazil.

\begin{abstract}
This thematic issue called Opportunities \& Challenges for Operations Management of the Brazilian Journal of Operations and Production Management (BJO\&PM) presents contemporaneous discussions of operations management, which is valuable for both the Brazilian and international audience. The papers presented in this thematic issue are selected based on articles and presentations performed in the "2018 POMS International Conference in Rio", held under the theme "Operations Management for social good". This introductory paper evaluates and summarizes the selected contributions of all papers presented in this thematic issue. The key topics emphasized in these papers are a real options approach for investment decision, business management, supply chain management, humanitarian logistics, and operations management.

Keywords: Operations Management; Supply Chain Management; Humanitarian Logistics and Operations; Social Good.
\end{abstract}


Brazilian Journal of Operations \& Production Management

Volume 16, Número 3, 2019, pp. 371-374

DOI: 10.14488/BJOPM.2019.v16.n3.a1

\section{INTRODUCTION}

The 2018 POMS International Conference in Rio (2018 POMS Rio), held at PUC-Rio, Rio de Janeiro - Brazil in December 2018, addressed the theme "Operations Management for Social Good". This international conference was organized by the POMS Caribbean \& Latin American Chapter and provided an opportunity for faculty, doctoral students and practitioners to share knowledge and insights through 167 research presentations grouped in 47 sessions, 3 tutorials, and 3 plenary sessions that contributed to the improved understanding and practice of production and operations management (POM).

This Thematic Issue of the Brazilian Journal of Operations \& Production Management (BJO\&PM) brings together some of the most significant papers and presentations addressing aspects of the issues presented at the 2018 POMS Rio. Thus, this thematic issue comprises this introduction paper, the extended versions of ten relevant conference papers recommended by the conference committee, and four invited papers based on tutorials performed in the conference by outstanding professors.

\section{Overview of the Thematic Issue Papers}

The research conducted by Carolina Lopes, Frances Blank and Davi Valladão, "Investment decisions in an oil refinery in Brazil under a real options approach", proposes an application of the real options theory in the refining industry based on data from an oil refinery in Brazil. The paper evaluates the option to postpone the decision based on a deterministic or stochastic investment, the opportunity to shut down the refinery operation temporarily, and the interaction between both options. Moreover, the analysis considered different deadlines and the remaining amount of investment required to achieve a full refinery operation. The results revealed consistent analysis in some contexts; situations of residual investment amount lead to different decisions according to the expiration year. For example, the postponement of the project for the remaining investment was the best decision if the option to wait to invest is considered perpetual; however, in case of expiration within one year, most of the cases led to the immediate investment recommendation. As future research, the authors recommend the inclusion of other variables that could impact the decision, such as gas price, and other approaches, as the stochastic analysis.

The research conducted by Diego Clemente, Juliana Hsuan, and Marly de Carvalho, "Business Model Innovation and Modularity: overview of the literature" delivers a literature review integrating business model innovations and the modularity concept. The review was conducted through the ISI Web of Science and Scopus databases, presenting some bibliometric analysis. The most prominent analysis involves the co-citation network, which indicates that the literature can be grouped in three main groups discussing the following issues: (i) dynamic capabilities and business models, (ii) modularity in a wide range of topics, and (iii) modularity considering an organizational perspective. The authors also indicate future research on the application of modularity to business models and business model innovation, mainly exploring the modularity in services, as well as discussion of firm performance based on such applications.

A research group from University of São Paulo - São Paulo, Brazil (Pèra, Bartholomeu, Su, and Caixeta Filho) presents an analysis entitled "Evaluation of green transport corridors of Brazilian soybean exports to China". The paper defines a model to minimize the total average greenhouse gas emissions, considering six scenarios involving the transport of soybeans from the producing farms in the Brazilian Center-West to the main Brazilian export ports and, subsequently, to China, through the various logistical infrastructures available. The results suggest the configuration of optimum soybean flows, the respective level of utilization of multimodal terminal, also recommending the investments in rail and port terminals for greener logistics.

In the paper "Sustainable Practices and the Relationship with Suppliers in SSCM: a case study in Wholesale", Rosa, Abdala, and Cesarino present a case study considering data from multiple sources to analyze one of the biggest wholesaler-distributor of Latin America. The authors observed that the organization understands the importance of belonging to a sustainable supply chain, exploring the relationship with other members in the supply chain, focusing on the generation of value based on the Triple Bottom Line dimensions. Nevertheless, the authors identified that sustainability is not considered as an institutional value for the company as a whole, which is reinforced by the adoption of sustainability practices only recently. Thus, the case study reinforced previous research that indicates that awareness and concerns about the sustainability concept itself are not enough to create a sustainable chain.

Seeling, Scavarda, Thomé, and Hellingrath discuss sales and operations planning (S\&OP), considering the perspective of a multinational chemical corporation that operates in more than 110 countries. The authors applied a case study methodology with multiple sources of data that enable a robust perspective of the subject and analysis. Developed through structure procedures and theoretical references, the main results point that the S\&OP has been a central process to organize and to align the enterprise's efforts and deliver its business objectives. While the paper presents such an in-depth analysis of the organization, as indicated by the authors, this paper also contributes to fill a research gap related to the discussion of different real-life settings and data. Moreover, the authors reinforce perspectives for future research, for example, mature models in S\&OP.

The paper "Lessons from Empirical Studies in Supply Chain Flexibility: a Maturity Perspective" is developed by Mello, Hellingrath and Martins and applies a case study with three mul- 
tinational manufacturing companies. The research considered five dimensions (i.e., Information Sharing, Collaboration, Information Technology, Internal Flexibility, and Performance Measurement) to analyze the flexibility level. The contributions are wide-ranging as the research assess the maturity level of each company, identifies empirical challenges in such assessments, and proposes future research with other companies from the same industrial sector and with a higher level of flexibility.

In the invited paper "Social license to operate, the perspective from professionals of Brazilian extractive companies", Faria, Vieira Neto, and Quelhas apply a survey with experienced professionals to discuss the main practices relate to social license to operate. Despite the consideration of Brazilian experts involved with the sector of extractive companies, the results indicate a low awareness of scientific references about the subject, both from academic and practitioners' sources. Nevertheless, the authors provide a model to discuss the subject under the perspective of community relationship management and suggest future research to expand the investigation by the integration of other stakeholders' perspective.

The paper developed by Anna Lisa Junge is a systematic literature review entitled "Digital transformation technologies as an enabler for sustainable logistics and supply chain processes - an exploratory framework". The research analyzes 62 papers, provides a framework based on the Reference Architecture Model Industry 4.0 and also locates the existing discussions in this framework. The results identify specific digital technologies that are discussed in specific logistic and supply chain management practices and stages in the supply chain and reinforce the gap of research on digital technologies from an end-to-end perspective of the supply chain. The author suggests the expansion of the literature review to other databases and publications in languages other than English, and the development of more case studies to enhance the discussions on the subject.

In the paper "Prioritization of strategic initiatives in the context of natural disaster prevention", the authors da Silva and Belderrain developed a multicriteria evaluation model to prioritize the strategic actions for Cemaden (Brazilian Center for Monitoring and Early Warning of Natural Disasters). The sensibility analysis indicates the robustness of the model, and show the relevance of some alternatives, such as mobile application for communication and flood forecasting using nowcasting. Besides the significance of the application, the authors observe the importance of considering other stakeholders in the model in future research, e.g. beneficiaries of disaster warning, top managers at Cemaden, and specialists.

The paper "The use of Airpower on Humanitarian Operations: a case study in Brazil" is developed by Rodrigo Silveira and discusses the benefits reached with the use of airpower resources during humanitarian operations. The research applies the case study method to analyze a high impact disaster in
Brazil, where the Brazilian Air Force was involved. Besides the increased speed, mobility, flexibility, penetration, range, and readiness, the data indicate the strengthening of operational capabilities after such airpower engagement. Thus, the main contribution of this paper lies in the discussion of real data to reinforce the relevance and benefits related to the use of airpower in humanitarian operations.

The paper developed by Brito Júnior, Huivin and Chong, entitled "Impact of the urban logistics and pedestrian mobility Gamarra case, Peru", proposes a methodology to assess the risk of regions characterized by high population density also vulnerable to disaster. The main academic contribution is the definition of logistic variables that are relevant to an eventual evacuation of the local population and their consideration in the risk assessment of vulnerable regions. Besides that, the authors identified the critic microregions in the case study analyzed and recommended the government to implement this methodology into the public policies.

The paper developed by Sathler et al., "Integration of Facility Location and Equipment Allocation in Health Care Management", proposed an integrated model that simultaneously locates health unit centers and allocates equipment to maximize the coverage demand for specialists and medical examination. The model application considered real data from Minas Gerais, the second most populous state in Brazil, and brought valuable analysis to be considered by policymakers. The research investigated alternatives to maximize the satisfaction for medical specialties, considering an equity concept, and the data suggests that the gain in demand coverage is limited to a set number of medical specialist centers in specific regions. The practical contributions are various, and they are mainly related to the reduction of patients' expenses with displacement to get access to health unit centers, or cost reduction on the complementary activation of private hospitals by the public system.

Andrea Santos, professor at Université de Technologie de Troyes, France, composes the thematic issue with the invited paper "New Trends and Opportunities in Post-Disaster Relief Optimization Problems". The article discusses the application of optimization models on disaster response, immediately after the disaster occurs, with the use of real data and delivery of technical and real contribution for the professionals responsible for providing the humanitarian assistance. Moreover, the paper discusses some examples of the projects involved in this initiative, such as the location problem investigated for the earthquake that struck Kathmandu in 2015. The relevance lies in the identification of complex issues that should be considered in such applications of optimization problems in disaster relief operations as well as technological tools.

Winkler and Zinsmeister, professors at University of Applied Sciences Esslingen, Germany, add relevant discussions to this thematic issue through the invited paper "Trends in Digita- 
Brazilian Journal of Operations \& Production Management

Volume 16, Número 3, 2019, pp. 371-374

DOI: 10.14488/BJOPM.2019.v16.n3.a1 lization of Intralogistics and the Critical Success Factors of its Implementation". The research develops a survey with professionals involved with digitalization initiatives and intralogistics aiming to validate the results of two recent literature reviews. The first identifies the main digital trends in intralogistics, and the second identifies the critical success factors of digitalization projects in intralogistics. The results considered the perspective of 105 respondents, both academics and practitioners, mainly from Germany and Brazil, and reinforced the findings obtained in the previous systematic literature reviews. Thus, the authors propose several venues as future research, such as the investigation of interdependencies and mutual influences of both trends and success factors.

\section{FINAL REMARKS}

The papers presented in this thematic issue provide an exciting contribution to the research field of Operations Management by offering a broad look at key challenges for practitioners and academic researchers. The papers promote stimulating reading on production research, operations management, and industrial engineering for different audiences. BJO\&PM readers can find new perspectives and empirical contexts into several research areas of Supply Chain Management.

\section{Acknowledgments}

The co-editors of this thematic issue would like to thank the support and incentive of Dr. Osvaldo L. G. Quelhas, editor-in-chief of the Brazilian Journal of Operations and Production Management; and Izabela S. Rampasso, the editorial assistant. We also acknowledge the grateful help from the several thematic issue reviewers, who are top scholars in the area of Operations Management and Supply Chain Management. Finally, we are particularly grateful to the authors of the papers who have expended huge effort in following and respecting the tight deadlines.

\section{Biography}

Adriana Leiras is an Associate Professor in the Industrial Engineering Department at the Pontifical Catholic University of Rio de Janeiro - PUC-Rio (Rio de Janeiro, Brazil), as well as founder and coordinator of the HANDs Lab - Humanitarian Assistance and Needs for Disasters (http://www.hands.ind. puc-rio.br). She is also a Research Affiliate of the Post-Graduate Program in Logistic Systems Engineering at the University of São Paulo - USP (São Paulo, Brazil) and the master program in Humanitarian Logistics and Management (MASHLM) at the University of Lugano (Switzerland). She is the President of the POMS Caribbean \& Latin American Chapter and was the General Chair of the 2018 POMS International Conference in Rio. She also leads the regional research project in Humanitarian logistics and relief operations of the MIT SCALE Latin America Network. Since 2011, she has participated in research and consulting projects on the theme of humanitarian logistics and disaster management operations and co-authored papers that were published in conference proceedings and journals. She teaches and researches in Production Engineering, focusing on operations management and supply chain risk management in the context of humanitarian operations.

Contact: adrianaleiras@puc-rio.br

Tharcisio Cotta Fontainha is a professor at the Production Engineering Program of the Federal University of Rio de Janeiro, Project Coordinator at the Humanitarian Assistance and Needs for Disasters (HANDs, Brazil), and an Associated Researcher and Theses Supervisor at Master of Advanced Studies in Humanitarian Logistics and Management (MASHLM, USI, Switzerland). His research interest is in strategic relationships and process management in disaster and humanitarian operations, focusing on the interactions among stakeholders from private, public and social groups. He has experience in research projects involving reference models for Organizational Management, Knowledge Management, Reliability Management and Industrial Safety (UFRJ, Brazil). Since 2014, he has participated in research and consulting projects on the theme of humanitarian logistics and disaster management operations and co-authored papers that were published in conference proceedings and journals. In 2019 his thesis received an Honorary Mention in HUMLOG Best theses Award.

Contact: fontainha@pep.ufrj.br

Received: 22 Jul 2019

Approved: 22 Jul 2019

DOI: 10.14488/BJOPM.2019.v16.n3.a1

How to cite: Leiras, A. and Fontainha, T. C. (2019), “Opportunities \& Challenges for Operations Management - A point of view from the 2018 POMS International Conference in Rio", Brazilian Journal of Operations \& Production Management, Vol. 16, No. 3, pp. 371-374, available from: https://bjopm.emnuvens.com.br/bjopm/article/ view/878 (access year month day). 